\title{
Cell Cycle Checkpoint Protein RAD17
}

National Cancer Institute

\section{Source}

National Cancer Institute. Cell Cycle Checkpoint Protein RAD17. NCI Thesaurus. Code C91361.

Cell cycle checkpoint protein RAD17 (681 aa, 77 kDa) is encoded by the human RAD17 gene. This protein is involved in the mediation of both cell cycle arrest and DNA damage repair. 